\title{
Genetic conflict, genomic imprinting and establishment of the epigenotype in relation to growth*
}

\author{
Tom Moore \\ Department of Biochemistry, University College Cork, Lee Maltings, Prospect Row, Cork, Eire
}

\begin{abstract}
Genomic imprinting is the process that differentially modifies the parental alleles at certain genetic loci in the parental germlines. Such modifications of DNA and chromatin are somatically heritable and cause unequal expression of the parental alleles during subsequent development. In mammals, imprinted genes encode a relatively small number of functionally heterogeneous proteins. Nevertheless, imprinted genes exert important effects, primarily on fetal development, and their deregulation is implicated in a variety of pathologies including sporadic, inherited and induced growth disorders. Imprinted loci show several unusual structural and functional characteristics that may be related to mechanistic aspects of mono-allelic expression or to modes of evolution of imprinted genetic loci. Typically, imprinted genes are clustered in certain genomic regions and have relatively reduced intronic DNA content relative to non-imprinted genes. In addition, their regulatory regions frequently contain a combination of features including tandem repeats associated with differentially methylated $\mathrm{CpG}$ islands and overlapping transcription of coding or non-coding RNAs. The evolution of imprinting can be understood as the stable outcome of sexual selection acting differently on the parental alleles of genes that influence parental investment in offspring. Consistent with this explanation, imprinted genes are expressed predominantly during embryonic and postnatal development in mammals and in the developing endosperm of plants, and maternal or paternal expression at imprinted loci is associated with reduced or increased parental investment, respectively. Such selective forces have implications for understanding mechanistic aspects of genome reprogramming in the early mammalian embryo.
\end{abstract}

Genomic imprinting is the process that differentially marks certain chromosomes, sub-chromosomal domains or individual gene loci, resulting in the differential expression of the parental alleles in the somatic tissues during subsequent development. The occurrence of genomic imprinting in mammals was implied by a parental origin effect on certain mouse mutations and by the failure of parthenogenetic mouse embryos to develop to term (reviewed in Dyban and Baranov, 1987). Subsequently, the observation of contrasting phenotypes in mice either maternally or paternally disomic for various chromosome regions (reviewed in Cattanach and Beechey, 1997), and in gynogenetic and androgenetic mouse embryos produced using micromanipulation (Barton et al., 1984; McGrath and Solter, 1984), reinforced the impression that maternal and paternal duplications caused reduced and increased growth (particularly of the placenta), respectively, and contrasting behaviours in neonatal mice.

Email: t.moore@ucc.ie

*This article is based on a presentation given at the British Society of Animal Science symposium 'Early Regulation of Mammalian Development' held in Aberdeen in September 2000.
The major fetal growth factor, insulin-like growth factor 2 (Igf2), was the first imprinted gene to be identified in mammals and extensive searching in many laboratories has produced approximately 50 additional imprinted loci in mice and humans (the current list is available at www.mrc.mgu.ac.uk). The imprinted genes discovered to date are diverse in their genomic structure and encoded function. The number of identified imprinted genes is small and is unlikely to increase significantly in the future. This view is supported by empirical evidence and is consistent with evolutionary considerations which indicate that although many loci might evolve under the selective forces that promote imprinting, there are strong constraints that prevent the fixation of imprinted alleles. However, the fact that there is a small number of imprinted genes should not relegate them as subjects for intensive study for two related reasons: (i) deregulation of imprinted loci almost invariably results in major growth or other abnormalities; (ii) the imprinting process seems to be highly susceptible to a variety of environmental insults, with significant implications for its role in congenital growth disorders and cancer. 
The selective force underlying the evolution of imprinting has been understood for more than a decade (Haig and Westoby, 1989; Moore and Haig, 1991; Haig, 1992). What is less well understood is to what extent the 'conflict' theory of imprinting can be applied directly, in a predictive sense, to aspects of imprinted gene regulation, and deregulation in pathology. The aim of this article is to integrate our understanding of the evolution of imprinting with certain mechanistic features of imprinted genes and to speculate on the implications for the disease mechanism of 'loss of imprinting'.

\section{Evolution of imprinting}

Genomic imprinting in somatic tissues occurs in the developing mammalian embryo and neonate, and in the endosperm (food store) of plant seeds (Moore and Haig, 1991; Fig. 1). Despite some claims to the contrary, there is no evidence of adaptive imprinting in the somatic tissues of zebrafish or fowl (Corley-Smith et al., 1996; O'Neill et al., 2000). The unusual phylogenetic and ontogenetic distribution of imprinting is explained by only one theory - the 'conflict' theory (Moore and Haig, 1991; Haig, 1992). No other theory can explain this most basic feature of imprinting in somatic tissues and no significant facts have emerged to challenge the theory in the past decade (Haig, 1999; Moore and Mills, 1999).

It is axiomatic that, because reproductive success is allied to resource consumption, resource availability will become a factor limiting reproductive output. This means that an individual's reproductive fitness will be adversely affected by other individuals, including relatives, competing for the same resource pool (Trivers, 1974). Offspring (whether embryonic or neonatal mammals, or plant embryos) compete with each other for maternally derived resources and there are the expected trade-offs between future reproductive fitness of self and siblings outlined above. The genetic fall-out from such inter-sibling rivalry is complex but, in most instances, can be described by Hamilton's rule which identifies, in an intuitively satisfying manner, the degree of relatedness between siblings as the critical factor determining the value of the cost:benefit ratio (trade-off index) of an allele that can achieve fixation (Hamilton, 1964; Trivers, 1974). The asymmetric nature of the selective force that promotes unequal expression of the parental alleles at loci that influence resource acquisition is determined by the reduced relatedness of paternal alleles relative to maternal alleles in polyandrous mating systems. These arguments are supported by game theoretical and quantitative genetic models and their plausibility can hardly be questioned, given the simplicity of the starting assumptions and the excellent fit with experimental observations (Moore and Haig, 1991; Haig, 1992; Mochizuki et al., 1996; Spencer etal., 1998).

What, then, are the key predictions of the conflict theory in relation to the evolution of imprinting at autosomal loci?

\section{Polyandry}

From Hamilton's rule, the genetic relatedness asymmetries that result in differential selection on the parental alleles occur exclusively in polyandrous populations, that is, when a female's progeny are sired by more than one male (Moore and Haig, 1991; Haig, 1992). The degree of polyandry required to promote imprinting is unknown; however, it has been suggested that nothing more than the occasional death of a proportion of females' current mates, followed by replacement in subsequent reproductive cycles by unrelated males, may be sufficient (Haig, 1999). Certainly, this prediction is difficult to test given the scarcity of true monogamy, and the only serious attempt to do so in mice gave equivocal results (Vrana et al., 1998).

\section{Ability of paternal alleles in offspring to influence maternal investment}

Genetic relatedness asymmetries between maternal and paternal alleles in offspring may be translated into differential expression if such differences are selected by alterations in maternal investment. In other words, a new imprinted paternal allele must receive a pay-off in terms of increased maternal investment to its offspring. Access of paternal alleles to maternal resources is therefore crucial (Moore and Haig, 1991). This condition in satisfied in mammals and plants because the embryo remains attached to the mother after fertilization and paternal genes can influence maternal investment in offspring by influencing placental development, post-natal growth and suckling behaviour in mammals, and endosperm development in plants. Recently, imprinting of the insulin-like growth factor 2 gene (IGF2) has been found in marsupials but not in birds, consistent with the conflict theory ( $\mathrm{O}^{\prime} \mathrm{Neill}$ et al., 2000). However, it is not inconceivable that imprinting could evolve in non-viviparous polyandrous species, for example, at loci that influence post-hatching begging behaviour in birds. Here, the way in which imprinted gene expression evolves would presumably depend on whether one or both parents provision nestlings.

\section{Directional effects of parental alleles on maternal investment in offspring}

From Hamilton's rule, and consistent with quantitative genetic models, it is expected that, at imprinted loci, paternal alleles will favour a higher degree of maternal investment in offspring than maternal alleles (Haig and Westoby, 1989; Moore and Haig, 1991; Haig, 1992). The pattern of phenotypic abnormalities that follows duplications of imprinted loci in mice and plants, and the pattern of allelic silencing at most imprinted loci supports this prediction (Moore and Haig, 1991). For example, the oppositely imprinted Igf2 and Igf2 receptor (Igf2r) loci, the products of which interact antagonistically in the cell, promote opposite growth phenotypes (Haig and Graham, 1991). However, Hurst and McVean $(1997,1998)$ have 


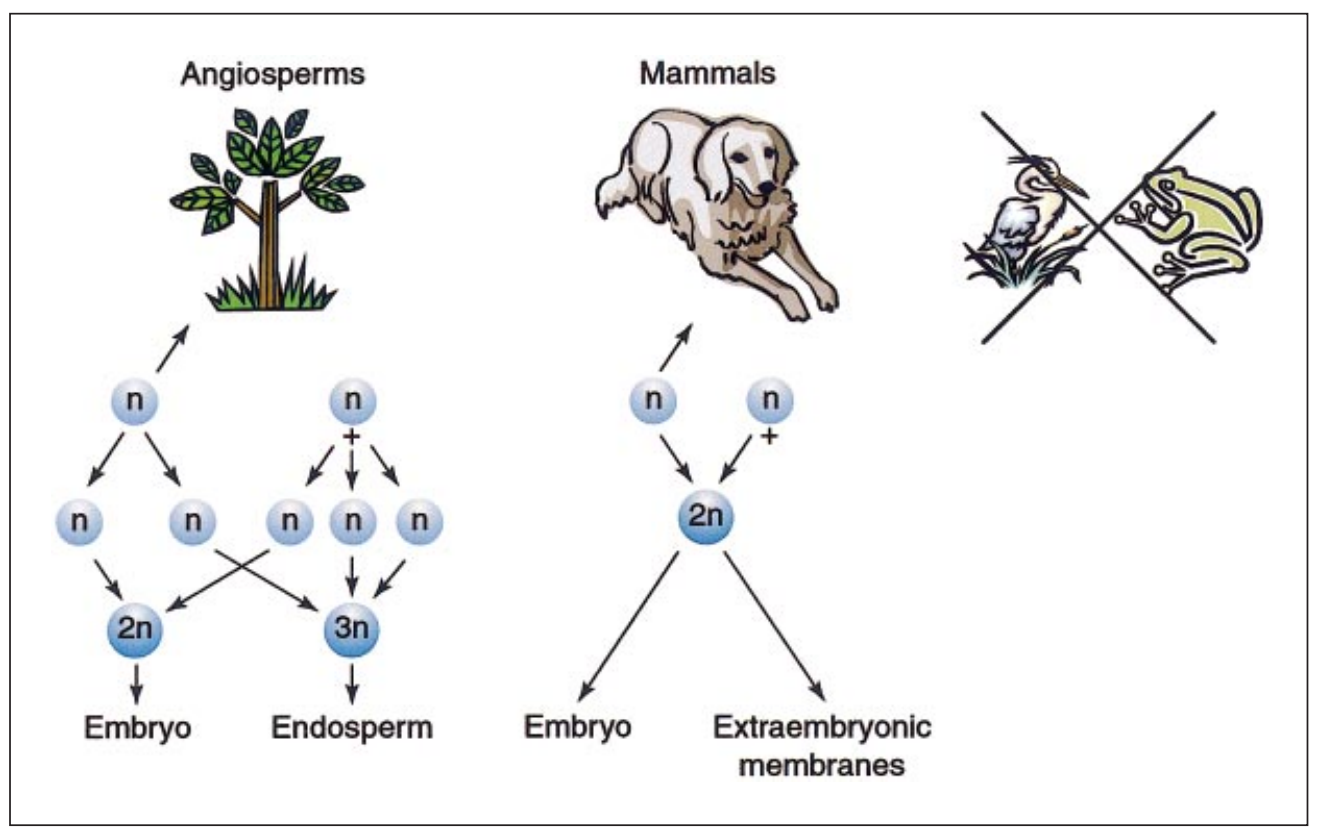

Fig. 1. The restricted phylogeny of imprinting. Parental allele-specific gene expression patterns are found at certain loci in mammals (see also Table 1) and plants. These groups satisfy the key requirements for the evolution of imprinting: parental investment in offspring, polyandrous mating systems, and opportunities for paternal genes in embryos to influence acquisition of maternal resources (Moore and Haig, 1991). In plants, the triploid endosperm acts as a food store for the embryo; in mammals, the extraembryonic membranes acquire nutrients for the fetus. In strictly oviparous species (birds, most reptiles and amphibians), the amount of maternal investment (yolk) is determined before fertilization, and therefore paternal genes cannot influence the extent of maternal investment.

been persistent critics of such data. However, it is my opinion that the perceived problems are greatly overstated, and that accumulating data on the molecular genetics and physiology of imprinted loci will resolve outstanding controversies in favour of the conflict theory.

\section{Transcriptional arms races and accelerated evolution}

The conflict theory of imprinting describes an example of 'intra-genomic genetic conflict'. Genetic loci involved in such conflicts may be subjected to iterated rounds of selection (arms races) that may have several consequences, including increased gene expression and rapid DNA sequence evolution. Some imprinted genes are highly expressed, for example lgf2 and H19 transcripts are abundant. However, it is difficult to derive objective data on this question without direct comparisons of expression in closely related, non-imprinting species. Rapid evolution of DNA sequences is more amenable to objective analysis and, unlike a collection of rapidly evolving immune genes, imprinted genes are highly constrained, contrary to expectation (McVean and Hurst, 1997a). Subsequent analyses have indicated an explanation: mono-allelic expression may expose imprinted genes to severe negative selection (Moore and Mills, 1999) and may also drive selection for a reduced mutation rate at imprinted loci, as for the X chromosome (McVean and Hurst, 1997b). The observation of reduced intronic content of imprinted genes may be indicative of selection for increased transcription (Hurst et al., 1996); however, a coherent experimental approach to this observation is not obvious.

\section{Constraints on evolution of imprinting}

There may be many hundreds or thousands of genes that influence maternal investment in offspring and that may be subject to selection for mono-allelic expression. However, slightly fewer than 50 imprinted genes have been described in mice and humans. In addition to their scarcity, imprinted genes show significant chromosome clustering and strong conservation between mice and humans (Table 1). These facts indicate that there are significant constraints on the evolution of imprinting, as discussed below.

Dosage sensitivity. Conflict theory indicates that iterated rounds of selection will promote incremental increases in transcription of one parental allele and concomitant decreases at the other allele (which, at equilibrium, is fully silenced). This process requires that incremental changes in gene dosage are ultimately translated into incremental changes in maternal investment. New alleles at a locus showing strong dominance cannot alter phenotype (maternal investment) in an incremental manner and, therefore, a transcriptional arms race leading to highly 
Table 1. Imprinted genes in mice

\begin{tabular}{|c|c|c|c|}
\hline Gene & Chromosome & $\begin{array}{l}\text { Repressed } \\
\text { allele }\end{array}$ & $\begin{array}{l}\text { Imprinted } \\
\text { in human? }\end{array}$ \\
\hline Nnat & 2 & M & \\
\hline Gnas & 2 & $\mathrm{P}$ & + \\
\hline Gnasxl & 2 & M & + \\
\hline Nesp & 2 & $\mathrm{P}$ & + \\
\hline Nespas & 2 & M & \\
\hline Sgce & 6 & M & \\
\hline Peg1/Mest & 6 & M & + \\
\hline Copg2 & 6 & $\mathrm{P}$ & + \\
\hline Copg2as & 6 & M & \\
\hline Mit1/1b9 & 6 & M & \\
\hline Peg3/Pw1 & 7 & M & \\
\hline Zim1 & 7 & $\mathrm{P}$ & \\
\hline Snrpn & 7 & M & + \\
\hline Snurf & 7 & M & + \\
\hline Magel2 & 7 & M & + \\
\hline $\mathrm{Ndn}$ & 7 & M & + \\
\hline Zfp127 & 7 & M & \\
\hline Zfp127as & 7 & M & \\
\hline Ipw & 7 & M & + \\
\hline Ube3a & 7 & $\mathrm{P}$ & + \\
\hline H19 & 7 & $\mathrm{P}$ & + \\
\hline $\operatorname{lgf} 2$ & 7 & M & + \\
\hline Igf2as & 7 & M & + \\
\hline Ins2 & 7 & M & \\
\hline Mash2 & 7 & $\mathrm{P}$ & + \\
\hline Kvlqt1 & 7 & $\mathrm{P}$ & + \\
\hline Kvlqt1as & 7 & M & + \\
\hline Tapa1/Cd81 & 7 & $\mathrm{P}$ & \\
\hline P57KIP2 & 7 & $\mathrm{P}$ & + \\
\hline Orctl2 & 7 & $\mathrm{P}$ & + \\
\hline Itm & 7 & $\mathrm{P}$ & + \\
\hline Impt1 & 7 & $\mathrm{P}$ & + \\
\hline Ipl/Tssc3 & 7 & $\mathrm{P}$ & + \\
\hline Rasgrf1 & 9 & M & \\
\hline Zac1 & 10 & M & + \\
\hline Meg1/Grb10 & 11 & $\mathrm{P}$ & + \\
\hline U2af1-rs1 & 11 & M & \\
\hline Dlk & 12 & M & \\
\hline Meg3/Gt12 & 12 & $\mathrm{P}$ & + \\
\hline Htr2a & 14 & $\mathrm{P}$ & \\
\hline $\operatorname{lgf} 2 r$ & 17 & $\mathrm{P}$ & \\
\hline Igf2ras/Air & 17 & M & \\
\hline Impact & 18 & M & \\
\hline Ins1 & 19 & M & \\
\hline
\end{tabular}

Adapted from www.mrc.mgu.ac.uk

asymmetric allelic expression is unlikely at such loci (Haig, 1992). The perception from the analysis of mouse null mutants and human disease loci is that a relatively small proportion of genes shows detectable dosage sensitivity, greatly reducing the number of target loci at which imprinting can evolve.
Developmental restriction. The transfer of maternal resources in mammals ceases at weaning. The conflict theory predicts that genes that act in pathways that do not influence maternal investment or that are expressed exclusively in adults will not be selected for imprinting (Moore and Haig, 1991). Most imprinted genes are expressed exclusively at embryonic and neonatal stages, or encode their major phenotypic effects predominantly at those stages. These observations support the conflict theory and indicate a further reduction in the availability of loci susceptible to evolution of imprinting.

Oocyte reprogramming. The mammalian oocyte has extensive nuclear reprogramming power as evidenced by the production of cloned offspring from somatic cell nuclei (Wilmut et al., 1998). These mechanisms must be broadly targeted to many different modifications of DNA and chromatin, presumably to remove a variety of proteins and covalent modifications (such as methylation) from sperm DNA. New imprints must 'run the gauntlet' of these very efficient reprogramming mechanisms, thereby limiting the range of epigenetic marks that will survive reprogramming and result in somatically heritable differences between the parental alleles (Moore and Haig, 1991; Moore and Reik, 1996).

\section{Interim conclusions}

The predictions of the conflict theory are in good agreement with observation. The ability of the theory to account for the phylogenetic distribution of imprinting is the strongest point in its favour and supervenes any perceived problems arising from the interpretation of complex mouse mutant or human clinical data (Hurst and McVean, 1997, 1998). Extensive support for verbal arguments has come from standard genetic models, based on realistic assumptions. These facts should increase our confidence in applying, where appropriate, the conflict theory to the interpretation of new experimental data.

\section{Mechanisms of imprinting}

Concomitant with the development of evolutionary theories of imprinting over the past decade has come the identification of new imprinted genes and significant insights into the mechanisms of imprinting. To a large extent these two strands (evolution and mechanisms) have progressed independently of one another. This is understandable because evolution is opportunistic and population genetic models have little predictive power at the level of molecular mechanisms (Moore and Collins, 1997). Nevertheless, certain predictions of conflict theory may be relevant to aspects of the phenomenon of pathological 'loss of imprinting', particularly following the manipulation of preimplantation embryos.

\section{Imprints}

An imprint is usually defined as a parental sex-specific epigenetic mark, applied to an allele in the parental 
germline, which is somatically stable upon transmission to progeny. Such parental imprints set up expression differences between the parental alleles in the somatic tissues during subsequent development. However, it is a common misconception that an imprint denotes a modification of DNA or chromatin that necessarily results in allelic silencing (Barlow, 1994). From an evolutionary perspective, an imprint could equally promote allelic differences by increasing the expression of one parental allele relative to the other. Therefore, an imprint should be understood as simply a difference between the epigenetic states of the parental alleles. In addition to somatic heritability, the other key feature of such epigenetic marks is their reversibility in the opposite parental germline to the one in which they were imposed.

\section{Reciprocal imprinting and growth: Igf2 and H19 as examples}

The Igf2 gene encodes a major fetal growth factor. The linked Igf2 and H19 genes were amongst the first imprinted genes to be discovered and they have been studied intensively using a variety of molecular genetic and gene targeting techniques in mice. These studies have identified some of the epigenetic modifications that constitute germline imprints at this locus, and a variety of functionally defined genomic elements, such as tissue-specific enhancers (Leighton et al., 1995; Webber et al., 1998; Ainscough et al., 2000), silencers (Feil et al., 1994; Moore et al., 1997; Constancia et al., 2000) and a putative boundary element (Hark et al., 2000; Szabo et al., 2000), have been mapped. In addition, these genes show many features found at other imprinted loci including tandem DNA repeats associated with regions of parental allelespecific DNA methylation and the production of non-coding transcripts (Moore et al., 1997; Figs 2 and 3).

In normal development, the paternal copy of H19 and the maternal copy of Igf2 are silenced. This pattern of reciprocal imprinting indicated that, on the same chromosome, lgf2 and $\mathrm{H} 19$ compete for mutually exclusive access to a set of cis-acting, tissue-specific enhancers, and early work supported this 'enhancer competition' model (Leighton et al., 1996). However, this model has been proven incorrect by the maintenance of the wild-type pattern of imprinting after deletion of the entire H19 promoter and transcription unit (Schmidt et al., 1999). Current work is focused on a region several kilobases upstream of the $\mathrm{H} 19$ promoter that shows many structural and functional features of a silencer or boundary element (Lyko et al., 1997; Brenton et al., 1999; Drewell et al., 2000). This region shows allele-specific DNA methylation (Bartolomei et al., 1993) and heterochromatinization (Banerjee and Smallwood, 1998; Hark and Tilghman, 1998; Khosla et al., 1999; Banerjee et al., 2000). Deletion of this region is sufficient to abolish imprinting of both the Igf2 and $H 19$ genes. Transmission of the deletion from the male parent results in activation of paternal $\mathrm{H} 19$ and silencing of paternal lgf2. Maternal transmission causes activation of the maternal Igf2 allele and, significantly, reduces expression of $H 19$, indicating that this imprinting control region contains a transcriptional enhancer (Thorvaldsen et al., 1998), which is consistent with the predictions of the conflict theory outlined earlier.

Detailed study of the Igf2 gene has revealed several silencer elements that, similar to the H19 imprinting control region, show allele-specific DNA methylation, but do not show allelic differences in nuclease sensitivity. In all cases examined, these silencers are fully responsive to the $\mathrm{H} 19$ imprinting control region and do not have autonomous imprinting activity (Feil et al., 1994; Moore et al., 1997; Constancia et al., 2000).

\section{Loss of imprinting and growth deregulation: Igf2 and H19 as examples}

Deregulation of imprinting at the lgf2-H19 locus is implicated in human pathology such as BeckwithWiedemann syndrome (BWS; a congenital overgrowth disorder), Wilm's tumour of the kidney (frequently associated with BWS) and many types of sporadic tumour (for examples, see Steenman et al., 1994; Reik et al., 1995; Feinberg, 1999). Loss of imprinting of human IGF2 (as judged by altered DNA methylation and biallelic expression of the parental alleles) occurs secondary to H19, or through H19-independent mechanisms. Work in mice supports both of these possibilities: deletions at the mouse $\mathrm{H} 19$ locus alter DNA methylation and expression patterns of Igf2 (Leighton et al., 1995; Drewell et al., 2000; Fig. 3b) and deletion of a region upstream of the lgf2 promoters causes biallelic expression of all Igf2 transcripts in mesodermal tissues, independent of H19 expression (Constancia et al., 2000; Fig. 3c).

These observations initially appeared to provide a comprehensive explanation for the various modes of production of overgrowth disorders such as BWS; however, recent work has added a new and highly significant dimension to the regulation of this genomic region in disease. More detailed analysis of BWS patients has shifted attention to a pair of reciprocally imprinted genes that are chromosomally linked to the IGF2-H19 locus, but regulated independently. One of these genes, CDKN1C ( $\left.557^{k i p 2}\right)$, is physiologically antagonized by IGF-II peptide (Caspary et al., 1999; Grandjean et al., 2000), the other, LIT1, is an untranslated RNA (Horike et al., 2000). The IGF2-H19 and p57kip2-LIT1 pairs may be two independently regulated imprinting clusters on human chromosome 11p.15.5 (Feinberg, 2000), which are nevertheless physiologically linked through interactions between IGF-II and p57kip2 proteins.

Renewed interest in the analysis of BWS patients after the discovery of the $p 57^{k i p 2}-L I T 1$ dimension has led to a radical reassessment of the aetiology of BWS. Loss of imprinting of LIT1 is found in about half of BWS patients, but not in Wilm's tumour. Loss of imprinting of IGF2 occurs in $20 \%$ of BWS patients and is a frequent finding in Wilm's and other tumours (Feinberg, 2000). 


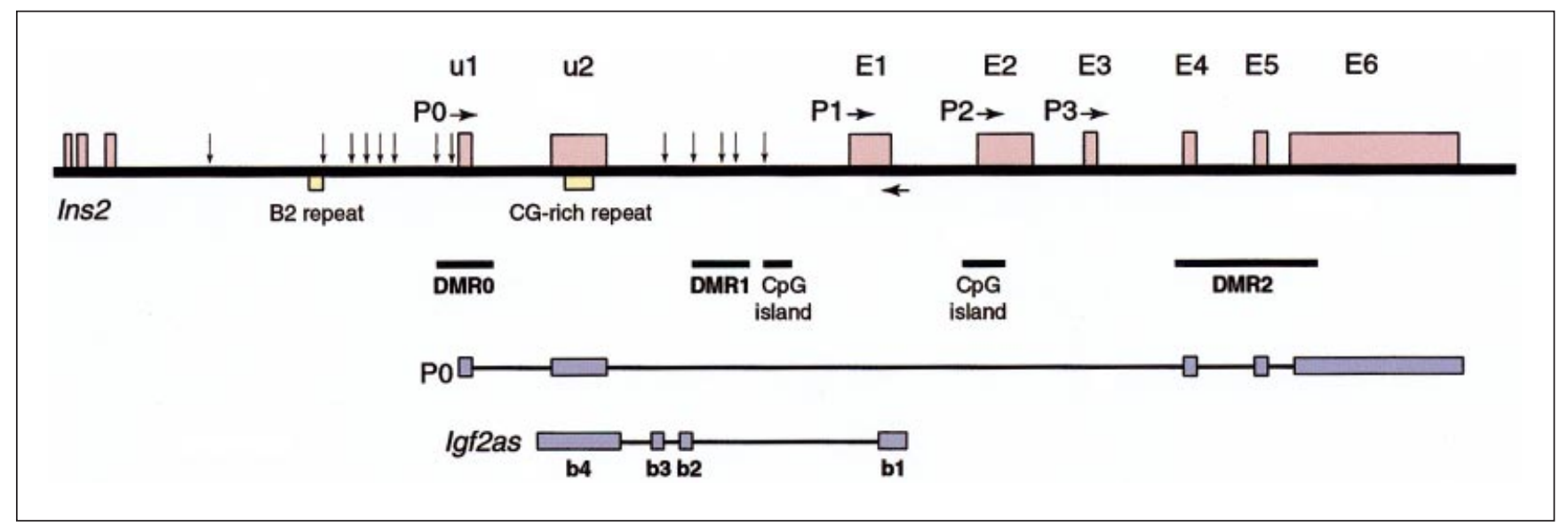

Fig. 2. Genomic structure of the mouse insulin-like growth factor 2 (Igf2) gene. Key features found in many imprinted genes are shown, including: differentially methylated regions (DMRs) associated with tandem repeats; overlapping sense and antisense transcripts, including transcribed non-coding RNA (Igf2as); low intronic content (few and small introns; Hurst et al., 1996). Igf2 promoters: P0, P1, P2, P3. lgf2 exons (filled boxes): u1, u2, E1, E2, E3, E4, E5, E6. Igf2as exons: b1, b2, b3, b4. Dnase I hypersensitive sites (vertical arrows) are found in the Igf2 'upstream region', but (unlike many other imprinted genes) do not show parental allele specificity (Moore et al., 1997).

\section{Implications for domestic species}

As noted earlier, there is a considerable degree of conservation between mice and humans in both the identity of imprinted genes and in mechanisms of imprinting. These findings can be extrapolated to domestic species with confidence and, indeed, the few studies in domestic species support a high degree of conservation of imprinting throughout the eutherian mammals (Feil et al., 1998; McLaren and Montgomery, 1999). With this in mind, it is interesting to note that the growth abnormalities observed in domestic ruminants after in vitro manipulation of preimplantation embryos bear more than a passing resemblance to those of human BWS (Young et al., 1998; Sinclair et al., 1999). Similar manipulations might also contribute to gestational losses after attempts at somatic cell cloning. The parallels between human pathology and embryo culture-induced 'large offspring syndrome' in ruminants have implicated the deregulation of imprinted genes in this syndrome (Moore and Reik, 1996; Young and Fairburn, 2000), and the IGF2-H19 and $p 57^{k i p 2}-$ LIT1 gene pairs or other BWS genes are good candidates.

\section{The timing of germline imprinting}

An appreciation of the timing of acquisition and subsequent modification of imprints in the germline and zygote is relevant to understanding the role of aberrant imprinting in the generation of the developmental abnormalities that result from certain manipulations of germ cells and early embryos. Two approaches have yielded information on this question. Firstly, the addition and removal of DNA methylation imprints has been analysed throughout germ cell and early embryonic development using methylation-sensitive PCR and related techniques. These studies underlined the temporal complexity of imprint regulation and found that removal of DNA methylation imprints early in germline development in both male and female embryos, and more variable addition of new imprints relatively late in meiosis (Davis et al., 2000; Kerjean et al., 2000; Ueda et al., 2000). Secondly, two research groups have used a developmental assessment of germ cell epigenotype switching to study this question (Kono et al., 1996; Obata et al., 1998; Tada et al., 1998; Bao et al., 2000). Both groups found that the regulation of Igf2 imprinting was different from that of other imprinted genes analysed. These results hint at the possibility that specific imprinted genes may be deregulated due to various manipulations in vitro, rather than there being global disruption of imprinting.

\section{Oocyte reprogramming revisited}

As discussed earlier, the oocyte contains mechanisms that are capable of significantly modifying the epigenotype. It has been noted that such mechanisms, because they are encoded entirely by maternal genes, represent a potential arena of intragenomic conflict between maternally encoded (oocyte) modifiers and paternal genes (Moore and Haig, 1991). Specifically, it was suggested that, after fertilization, maternal modifier genes would benefit by encoding the removal of paternal imprints on sperm DNA. It was further suggested that sperm cytosolic factors might evolve to antagonize the reprogramming of paternal imprints by such oocyte modifiers (Moore and Haig, 1991; Moore and Reik, 1996). If such mechanisms act during the early preimplantation period, their disruption by the manipulation of embryos in vitro may provide a basis for loss of imprinting in large offspring syndrome.

Recent work underlines the plausibility of such mechanisms. Active demethylation of sperm genes, but not 


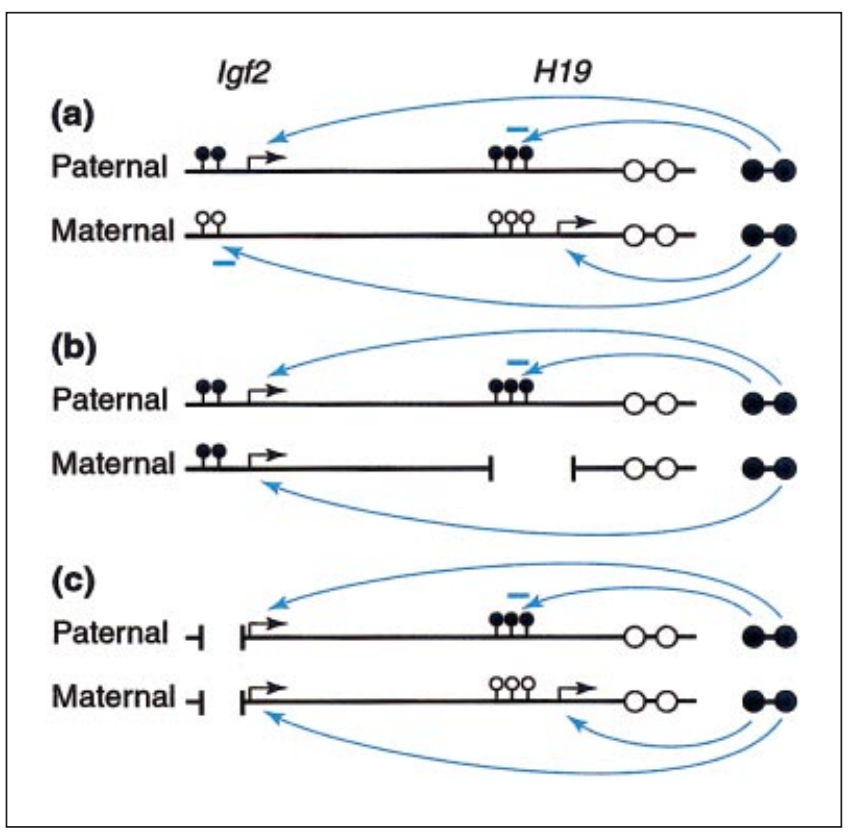

Fig. 3. Loss of imprinting of insulin-like growth factor 2 (Igf2) gene by H19-dependent and -independent mechanisms. Genomic map of Igf2-H19 locus spanning approximately $100 \mathrm{~kb}$. (a) At the wildtype locus, the DMR $5^{\prime}$ of the $H 19$ promoter is methylated, allowing activation of Igf2 by $\mathrm{H} 19$ enhancers. On the maternal chromosome the H19DMR is unmethylated and the H19 promoter is active. This is associated with silencing of the lgf2 gene. (b) Deletion of the H19 DMR and promoter on the maternal chromosome causes activation (loss of imprinting) of maternal Igf2. Similarly, in (c), deletion of the Igf2 DMR1 on the maternal chromosome (see Fig. 2) results in activation of maternal Igf2. Igf2 and H19 promoters: horizontal arrows; H19 tissue-specific 'downstream' enhancers: $\bigcirc$; silencer or enhancer activities: curved arrows; methylated CpGs: $\boldsymbol{\uparrow}$; unmethylated CpGs: $\boldsymbol{\uparrow}$; deletions denoted by horizontal line breaks bounded by vertical bars.

oocyte genes, occurs after fertilization (Oswald et al., 2000), indicating specific targeting of paternal genes by oocyte modifiers. This observation is consistent with an earlier demonstration of an interaction between maternal genotype-specific oocyte modifiers and paternal alleles, assessed through an influence on the development of androgenetic mouse embryos (Latham and Solter, 1991). The principle that culture in vitro of preimplantation embryos alters imprints has been demonstrated. Mouse embryos cultured in Whitten's medium showed biallelic H19 expression, whereas culture in KSOM (Erbach et al., 1994) containing amino acids had no effect. Aberrant expression of H19 in this experiment was accompanied by demethylation of the H19 imprinting control region. Significantly, other imprinted genes were not affected, indicating a specific susceptibility of $\mathrm{H} 19$ to this particular manipulation (Doherty et al., 2000).

There is strong evidence that environmental factors can influence DNA methylation both in vitro and in vivo. For example, polyamine depletion interferes with DNA methyltransferase activity and induces differentiation of cultured F9 teratocarcinoma stem cells (Frostesjo et al. 1997), and feeding of methyl-supplemented diets to pregnant agouti (a/a) mouse mutants alters epigenetic regulation of agouti expression in offspring (Wolff et al., 1998). Although such observations are suggestive, it remains to be determined whether large offspring syndrome in domestic ruminants represents a discrete syndrome resulting from deregulation of one or a small number of genes by a variety of environmental factors. It should be noted that deregulation of non-imprinted genes in cultured bovine embryos has been reported (Niemann and Wrenzycki, 2000), although it is unclear whether such differences are developmentally significant. However, the foregoing complexities notwithstanding, the phenotypic similarities between ruminant large offspring syndrome and human BWS remain suggestive and deregulation of imprinting remains a plausible candidate mechanism for large offspring syndrome (Young and Fairburn, 2000).

\section{Conclusions}

In the past decade, an enormous amount of progress has been made in understanding the evolution and mechanisms of imprinting, and the implications for normal and abnormal development. It is unlikely that many imprinted genes remain to be discovered; however, those already identified are proving to be a rich source for the discovery of novel mechanisms of gene regulation. The study of pathological loss of imprinting is likely to become increasingly significant both in relation to cancer and to concerns regarding the increasing interest in manipulating embryos of domestic species and humans for a variety of purposes.

\section{References}

Key references are identified by asterisks.

Ainscough JF, John RM, Barton SC and Surani MA (2000) A skeletal musclespecific mouse lgf2 repressor lies $40 \mathrm{~kb}$ downstream of the gene Development 127 3923-3930

Banerjee S and Smallwood A (1998) Chromatin modification of imprinted H19 gene in mammalian spermatozoa Molecular Reproduction and Development 50 474-484

Banerjee S, Singh PB, Rasberry C and Cattanach BM (2000) Embryonic inheritance of the chromatin organisation of the imprinted $\mathrm{H} 19$ domain in mouse spermatozoa Mechanisms of Development 90 217-226

Bao S, Obata Y, Carroll J, Domeki I and Kono T (2000) Epigenetic modifications necessary for normal development are established during oocyte growth in mice Biology of Reproduction 62 616-621

Barlow DP (1994) Imprinting: a gamete's point of view Trends in Genetics 10 194-199

Bartolomei MS, Webber AL, Brunkow ME and Tilghman SM (1993) Epigenetic mechanisms underlying the imprinting of the mouse H19 gene Genes and Development 7 1663-1673

*Barton SC, Surani MA and Norris ML (1984) Role of paternal and maternal genomes in mouse development Nature 311 374-376

Brenton JD, Drewell RA, Viville S, Hilton KJ, Barton SC, Ainscough JF and Surani MA (1999) A silencer element identified in Drosophila is required for imprinting of $\mathrm{H} 19$ reporter transgenes in mice Proceedings National Academy of Sciences USA 96 9242-9247 
Caspary T, Cleary MA, Perlman EJ, Zhang P, Elledge SJ and Tilghman SM (1999) Oppositely imprinted genes p57(Kip2) and igf2 interact in a mouse model for Beckwith-Wiedemann syndrome Genes and Development 13 3115-3124

Cattanach BM and Beechey CV (1997) Genomic imprinting in the mouse: possible final analysis. In Genomic Imprinting pp 118-141 Eds W Reik and A Surani. IRL Press, Oxford

Constancia M, Dean W, Lopes S, Moore T, Kelsey G and Reik W (2000) Deletion of a silencer element in igf2 results in loss of imprinting independent of H19 Nature Genetics 26 203-206

Corley-Smith GE, Lim CJ and Brandhorst BP (1996) Production of androgenetic zebrafish (Danio rerio) Genetics 142 1265-1276

Davis TL, Yang GJ, McCarrey JR and Bartolomei MS (2000) The H19 methylation imprint is erased and re-established differentially on the parental alleles during male germ cell development Human Molecular Genetics 9 2885-2894

*Doherty AS, Mann MR, Tremblay KD, Bartolomei MS and Schultz RM (2000) Differential effects of culture on imprinted H19 expression in the preimplantation mouse embryo Biology of Reproduction 62 1526-1535

*Drewell RA, Brenton JD, Ainscough JF, Barton SC, Hilton KJ, Arney KL, Dandolo L and Surani MA (2000) Deletion of a silencer element disrupts H19 imprinting independently of a DNA methylation epigenetic switch Development 127 3419-3428

Dyban AP and Baranov VS (1987) Haploidy (androgenesis, gynogenesis, parthenogenesis). In Cytogenetics of Mammalian Embryonic Development pp 5-39. Clarendon Press, Oxford

Erbach GT, Lawitts JA, Papaioannou VE and Biggers JD (1994) Differential growth of the mouse preimplantation embryo in chemically defined media Biology of Reproduction 50 1027-1033

Feil R, Walter J, Allen ND and Reik W (1994) Developmental control of allelic methylation in the imprinted mouse Igf2 and $\mathrm{H} 19$ genes Development 120 2933-2943

Feil R, Khosla S, Cappai P and Loi P (1998) Genomic imprinting in ruminants: allele-specific gene expression in parthenogenetic sheep Mammalian Genome 9 831-834

Feinberg AP (1999) Imprinting of a genomic domain of 11p15 and loss of imprinting in cancer: an introduction Cancer Research 59 (Supplement) 1743S-1746S

Feinberg AP (2000) The two-domain hypothesis in Beckwith-Wiedemann syndrome Journal of Clinical Investigation 106 739-740

Frostesjo L, Holm I, Grahn B, Page AW, Bestor TH and Heby O (1997) Interference with DNA methyltransferase activity and genome methylation during F9 teratocarcinoma stem cell differentiation induced by polyamine depletion Journal of Biological Chemistry 272 43594366

Grandjean V, Smith J, Schofield PN and Ferguson-Smith AC (2000) Increased IGF-II protein affects p57kip2 expression in vivo and in vitro: implications for Beckwith-Wiedemann syndrome Proceedings National Academy of Sciences USA 97 5279-5284

Haig D (1992) Genomic imprinting and the theory of parent-offspring conflict Seminars in Developmental Biology 3 153-160

Haig D (1999) Genetic conflicts and the private life of Peromyscus polionotus. Nature Genetics 22131

Haig D and Graham C (1991) Genomic imprinting and the strange case of the insulin-like growth factor II receptor Cell 64 1045-1046

Haig D and Westoby M (1989) Parent-specific gene expression and the triploid endosperm American Naturalist 134 147-155

Hamilton WD (1964) The genetical evolution of social behaviour I and II Journal of Theoretical Biology 7 1-52

Hark AT and Tilghman SM (1998) Chromatin conformation of the H19 epigenetic mark Human Molecular Genetics 7 1979-1985

Hark AT, Schoenherr CJ, Katz DJ, Ingram RS, Levorse JM and Tilghman SM (2000) CTCF mediates methylation-sensitive enhancer-blocking activity at the H19/lgf2 locus Nature 405 486-489

Horike Si, Mitsuya K, Meguro M, Kotobuki N, Kashiwagi A, Notsu T, Schulz TC, Shirayoshi Y and Oshimura M (2000) Targeted disruption of the human LIT1 locus defines a putative imprinting control element playing an essential role in Beckwith-Wiedemann syndrome Human Molecular Genetics 9 2075-2083
Hurst LD and McVean GT (1997) Growth effects of uniparental disomies and the conflict theory of genomic imprinting Trends in Genetics 13 436-443

Hurst LD and McVean GT (1998) Do we understand the evolution of genomic imprinting? Current Opinion in Genetics and Development 8 701-708

Hurst LD, McVean G and Moore T (1996) Imprinted genes have few and small introns Nature Genetics 12 234-237

Kerjean A, Dupont JM, Vasseur C, Le Tessier D, Cuisset L, Paldi A, Jouannet $\mathbf{P}$ and Jeanpierre $\mathbf{M}$ (2000) Establishment of the paternal methylation imprint of the human $\mathrm{H} 19$ and MEST/PEG1 genes during spermatogenesis Human Molecular Genetics 9 2183-2187

Khosla S, Aitchison A, Gregory R, Allen ND and Feil R (1999) Parental allele-specific chromatin configuration in a boundary-imprintingcontrol element upstream of the mouse $\mathrm{H} 19$ gene Molecular and Cellular Biology 19 2556-2566

Kono T, Obata Y, Yoshimzu T, Nakahara T and Carroll J (1996) Epigenetic modifications during oocyte growth correlates with extended parthenogenetic development in the mouse Nature Genetics 13 91-94

Latham KE and Solter D (1991) Effect of egg composition on the developmental capacity of androgenetic mouse embryos Development $113561-568$

Leighton PA, Saam JR, Ingram RS, Stewart CL and Tilghman SM (1995) An enhancer deletion affects both $\mathrm{H} 19$ and Igf2 expression Genes and Development 9 2079-2089

Leighton PA, Saam JR, Ingram RS and Tilghman SM (1996) Genomic imprinting in mice: its function and mechanism Biology of Reproduction $54273-278$

Lyko F, Brenton JD, Surani MA and Paro R (1997) An imprinting element from the mouse $\mathrm{H} 19$ locus functions as a silencer in Drosophila. Nature Genetics 16 171-173

McGrath J and Solter D (1984) Completion of mouse embryogenesis requires both the maternal and paternal genomes Cell 37 179-183

McLaren RJ and Montgomery GW (1999) Genomic imprinting of the insulin-like growth factor 2 gene in sheep Mammalian Genome $\mathbf{1 0}$ 588-591

McVean GT and Hurst LD (1997a) Molecular evolution of imprinted genes: no evidence for antagonistic coevolution Proceedings of the Royal Society of London Series B Biological Sciences 264 739-746

McVean GT and Hurst LD (1997b) Evidence for a selectively favourable reduction in the mutation rate of the $X$ chromosome Nature 386 388-392

Mochizuki A, Takeda Y and Iwasa Y (1996) The evolution of genomic imprinting Genetics 144 1283-1295

Moore T and Collins B (1997) From birds and bees to babies? Can theories on genetic conflict aid the clinician? Human Reproduction 12 2091-2092

*Moore T and Haig D (1991) Genomic imprinting in mammalian development: a parental tug-of-war Trends in Genetics 7 45-49

Moore T and Mills W (1999) Imprinting and monogamy Nature Genetics 22 130-131

Moore T and Reik W (1996) Genetic conflict in early development: parental imprinting in normal and abnormal growth Reviews of Reproduction 1 73-77

Moore T, Constancia M, Zubair M, Bailleul B, Feil R, Sasaki H and Reik W (1997) Multiple imprinted sense and antisense transcripts, differential methylation and tandem repeats in a putative imprinting control region upstream of mouse Igf2 Proceedings National Academy of Sciences USA 9412 509-12 514

Niemann H and Wrenzycki C (2000) Alterations of expression of developmentally important genes in preimplantation bovine embryos by in vitro culture conditions: implications for subsequent development Theriogenology 53 21-34

Obata Y, Kaneko-Ishino T, Koide T, Takai Y, Ueda T, Domeki I, Shiroishi T, Ishino F and Kono T (1998) Disruption of primary imprinting during oocyte growth leads to the modified expression of imprinted genes during embryogenesis Development 125 1553-1560

O'Neill MJ, Ingram RS, Vrana PB and Tilghman SM (2000) Allelic expression of IGF2 in marsupials and birds Development, Genes and Evolution 210 18-20 
Oswald J, Engemann S, Lane N, Mayer W, Olek A, Fundele R, Dean W, Reik W and Walter J (2000) Active demethylation of the paternal genome in the mouse zygote Current Biology 10 475-478

Reik W, Brown KW, Schneid H, Le Bouc Y, Bickmore W and Maher ER (1995) Imprinting mutations in the Beckwith-Wiedemann syndrome suggested by altered imprinting pattern in the IGF2-H19 domain Human Molecular Genetics 4 2379-2385

Schmidt JV, Levorse JM and Tilghman SM (1999) Enhancer competition between $\mathrm{H} 19$ and Igf2 does not mediate their imprinting Proceedings National Academy of Sciences USA 96 9733-9738

Sinclair KD, McEvoy TG, Maxfield EK, Maltin CA, Young LE, Wilmut I, Broadbent PJ and Robinson JJ (1999) Aberrant fetal growth and development after in vitro culture of sheep zygotes Journal of Reproduction and Fertility 116 177-186

Spencer HG, Feldman MW and Clark AG (1998) Genetic conflicts, multiple paternity and the evolution of genomic imprinting Genetics 148 893-904

Steenman MJ, Rainier S, Dobry CJ, Grundy P, Horon IL and Feinberg AP (1994) Loss of imprinting of IGF2 is linked to reduced expression and abnormal methylation of $\mathrm{H} 19$ in Wilms' tumour Nature Genetics 7 433-439

Szabo P, Tang SH, Rentsendorj A, Pfeifer GP and Mann JR (2000) Maternalspecific footprints at putative CTCF sites in the H19 imprinting control region give evidence for insulator function Current Biology 10 607-610

Tada T, Tada M, Hilton K, Barton SC, Sado T, Takagi N and Surani MA
(1998) Epigenotype switching of imprintable loci in embryonic germ cells Development, Genes and Evolution 207 551-561

*Thorvaldsen JL, Duran KL and Bartolomei MS (1998) Deletion of the H19 differentially methylated domain results in loss of imprinted expression of H19 and Igf2 Genes and Development 12 3693-3702

Trivers RL (1974) Parent-offspring conflict American Zoologist 14 249-264

Ueda T, Abe K, Miura A et al. (2000) The paternal methylation imprint of the mouse $\mathrm{H} 19$ locus is acquired in the gonocyte stage during foetal testis development Genes and Cells 5 649-659

Vrana PB, Guan XJ, Ingram RS and Tilghman SM (1998) Genomic imprinting is disrupted in interspecific Peromyscus hybrids Nature Genetics 20 362-365

Webber AL, Ingram RS, Levorse JM and Tilghman SM (1998) Location of enhancers is essential for the imprinting of $\mathrm{H} 19$ and lgf2 genes Nature $391711-715$

Wilmut I, Young L and Campbell KH (1998) Embryonic and somatic cell cloning Reproduction, Fertility and Development 10 639-643

Wolff GL, Kodell RL, Moore SR and Cooney CA (1998) Maternal epigenetics and methyl supplements affect agouti gene expression in Avy/a mice FASEB Journal 12 949-957

*Young LE and Fairburn HR (2000) Improving the safety of embryo technologies: possible role of genomic imprinting Theriogenology 53 627-648

Young LE, Sinclair KD and Wilmut I (1998) Large offspring syndrome in cattle and sheep Reviews of Reproduction 3 155-163 